\title{
Changes in Synapsin Levels in the Millipede Gymnostreptus olivaceus Schubart, 1944 Exposed to Different Concentrations of Deltamethrin
}

\author{
Annelise Francisco, ${ }^{1}$ Pablo H. Nunes, ${ }^{2}$ Roberta C. F. Nocelli, ${ }^{3}$ and Carmem S. Fontanetti ${ }^{1, *}$ \\ ${ }^{1}$ Departamento de Biologia, Instituto de Biociências de Rio Claro, Universidade Estadual Paulista (UNESP), Bela Vista, \\ 13.500-900, Rio Claro, São Paulo, Brazil \\ ${ }^{2}$ Centro Interdisciplinar de Ciências da Vida e da Natureza (CICV), Instituto Latino-Americano de Ciências da vida e da \\ Natureza (ILACVN), Universidade Federal da Integração Latino-Americana (UNILA), Avenida Silvio Américo Sasdelli, 1842, \\ 85.866-000, Foz do Iguaçu, Paraná, Brazil \\ ${ }^{3}$ Departamento de Ciências da Natureza, Matemática e Educação, Centro de Ciências Agrárias, Universidade Federal de São \\ Carlos (UFSCar), Via Anhanguera, Km 174, 13.600-970, Araras, São Paulo, Brazil
}

\begin{abstract}
Millipedes are ecologically important soil organisms and may also be an economically threatening species in rural and urban areas when population outbreaks occur. In order to control infestations commercial formulations of deltamethrin have been commonly applied, even though there are few studies about the effects of such insecticide on millipedes. This paper describes the effects of this insecticide on millipedes showing neurotoxic effects assessed by synapsin labeling and confocal microscopy. Deltamethrin concentrations related to the $\mathrm{DL}_{50}$ of the active ingredient and a field concentration were applied topically in the diplopod Gymnostreptus olivaceus to evaluate the behavior, mortality rate, and synapsin levels in the brain 12,24 , and $48 \mathrm{~h}$ after contact with deltamethin. The insecticide caused mortality at the higher concentrations employed, in which no change was observed in neurotransmission in the survivors. In contrast, at field concentrations, deltamethrin did not cause any deaths, but triggered significant changes in synapsin levels. The results obtained form the synapsin labeling provide several interpretations suggesting that the isolated application of this tool must be associated with additional tools in order to evaluate biologically induced effects of deltamethrin in an accurate way. In addition, the feasibility of chemical control of millipedes with deltamethrin is questioned.
\end{abstract}

Key words: arthropod, confocal microscopy, diplopod, olfactory glomeruli, pyrethroid

\section{INTRODUCTION}

Millipedes are terrestrial arthropods of the class Diplopoda, whose predominant life form is stratobiont, characterized by inhabiting upper layers of soil and litter (Hopkin \& Read, 1992; Golovatch \& Kime, 2009). Ecologically, these animals belong to the decomposer trophic level, taking part in nutrient cycling (Schubart, 1942; Petersen \& Luxton, 1982; Hopkin \& Read, 1992). In addition, millipedes aerate the soil while mixing the humus and mineral contents of the soil promoting its physical improvement (Romell, 1935; Fontanetti, 1989).

Despite providing benefits for soil fertility, millipedes can become agricultural and urban pests when environmental imbalances and climate changes trigger population outbreaks. Millipedes species are known to damage newly germinated seedlings, roots, and fruits in crops, leading to economic loss in rural areas worldwide (Lordello, 1954; Winder et al., 1993; Wightman \& Wightman, 1994; Ebregt et al., 2004a, 2004b). In urban environments, migration and demographic explosions of millipedes are also reported (Cloudsley-Thompson, 1949; Niijima \& Shinohara, 1988; Boccardo et al., 2002; Fontanetti et al., 2010). Their presence

Received July 21, 2015; accepted November 30, 2015

${ }^{*}$ Corresponding author. fontanet@rc.unesp.br in high number in such environments is undesirable and their appearance is usually considered repulsive. Contact with their defensive glandular secretions may also result in epidermal reactions in some people (Girardin \& Steveson, 2002; Arab et al., 2003; Ruppert et al., 2005).

Thus, a fast and effective means to control infestations of such organisms is demanded. Deltamethrin, a type II synthetic pyrethoid (Chen et al., 2007) has been popularly used for this purpose, even though there is no indication from the manufacturers of its effectiveness against millipedes. This insecticide class is characterized by its toxic effects on the target central nervous system (Larini, 1999).

Voltage-gated sodium channels are the main targets of pyrethroid insecticide action on invertebrates (Scharf, 2003; Zhou et al., 2011; Mccavera \& Soderlund, 2012), although several secondary targets of deltamethrin action are also reported (Soderlund et al., 2002). For example, studies on honeybees (Apis mellifera) found an increased acetylcholinesterase activity in individuals exposed to deltamethrin doses corresponding to deltamethrin's $\mathrm{LD}_{50}$ and half of this $\mathrm{LD}_{50}$ for the species (Badiou \& Belzunces, 2008; Badiou et al., 2008). Similarly, other secondary targets such as synapsin could also be affected by deltamethrin action.

Synapsins are located at presynaptic terminals of neurons. When a neuron is at rest, synapsin binds to synaptic vesicles, 
keeping them tethered to the actin cytoskeleton and away from the active zone, forming a reserve pool of synaptic vesicles (Hifiker et al., 1999; Cesca et al., 2010). When an action potential occurs, a cascade of events triggers the phosphorylation of synapsins. This change decreases its affinity both to synaptic vesicles and actin, resulting in the release of synaptic vesicles by exocytosis while the phosphorylated synapsins become dispersed in the cytoplasm (Huttner et al., 1983; Chi et al., 2003; Leitinger et al., 2004; Cesca et al., 2010; Benfenatti, 2011; Diegelmann et al., 2013).

This study aims to evaluate the control of millipedes by deltamethrin under experimental conditions, as well as evaluate the possible effects of this insecticide in the amount of synapsin in the somata of its olfactory glomeruli, as a way to infer neurotoxic effects. The species Gymnostreptus olivaceus (Spirostreptidae) was chosen for the tests since it can be found both in forests and cultivated areas. These millipedes were responsible for total loss of melon and beetroot crops in Piracicaba, São Paulo, Brazil, in 1952 (Lordello, 1954). Currently, millipedes of the species G. olivaceus are abundant in the region of study and may invade urban areas and damage home gardens.

\section{Materials and Methods}

Specimens of G. olivaceus were collected around the city of Rio

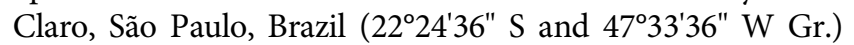
from March 2013 to February 2014 and kept in a terrarium with soil, leaves, wood residues, and potato slices, periodically moistened and kept at a constant temperature of $21^{\circ} \mathrm{C}$. The studies were conducted at São Paulo State University (UNESP) and all procedures involving animals were in accordance with the ethical standards of this institution.

We used plastic containers of $12 \mathrm{~cm}$ diameter $(530 \mathrm{~mL})$ lined with moistened filter paper to conduct the bioassays. Potato was provided ad libitum. Each container received one adult millipede weighing between 1.5 and $3.5 \mathrm{~g}$. Each millipede received $35 \mu \mathrm{L}$ of deltamethrin-water solution topically. The application was made on the dorsal surface of the millipedes with a micropipette for accurate dosing. A total of 120 millipedes were used for the experiment. Individuals were divided into one control group $\left(\mathrm{C}_{0}\right)$ and four treatment groups $\left(\mathrm{C}_{1-3}\right.$ and $\left.\mathrm{C}_{\mathrm{f}}\right)$ of 24 individuals each, kept in individual containers at $21^{\circ} \mathrm{C}$ in the dark throughout the bioassay.

Each treatment group was defined by the concentration of deltamethrin applied. The first group of individuals received a solution prepared at concentrations corresponding to one-fifth of the median lethal dose $\left(\mathrm{LD}_{50}\right)$ established by Boccardo et al. (2001), which is equivalent to $30.8 \mu \mathrm{g} / \mathrm{g}$ of deltamethrin $\left(\mathrm{C}_{1}\right)$; the second group was treated by the $\mathrm{LD}_{50}$ established in the species, whose value is $154 \mu \mathrm{g} / \mathrm{g}\left(\mathrm{C}_{2}\right)$; and the third by a solution in which the concentration correspond to twice the $\mathrm{LD}_{50}$, that is $308 \mu \mathrm{g} / \mathrm{g}$ of deltamethrin $\left(C_{3}\right)$. A field concentration $\left(C_{f}\right)$ which corresponds to the concentration based on recommendations from the manufacturer to combat infestations of other arthropods like
Ceratitis captata (Mediterranean fruit fly) and Agotis ipsilon (black cutworm) was also tested. For this an application of $0.17 \mu \mathrm{g}$ of the active ingredient per gram of animal's weight, equivalent to $0.11 \%$ of the above $\mathrm{LD}_{50}$, was used. The dilutions were made from a commercial product that contains $25 \mathrm{~g} / \mathrm{L}$ of deltamethrin and $886 \mathrm{~g} / \mathrm{L}$ of inert ingredients. The control group $\left(\mathrm{C}_{0}\right)$ received a topical application of $35 \mu \mathrm{L}$ of ultrapure water. Individuals were collected after 12, 24, and $48 \mathrm{~h}$ of exposure in order to assess the concentration effects, with three replicates collected for each concentration and time analyzed.

Millipedes were anesthesized by freezing and decapitated; the whole heads were fixed in $4 \%$ paraformaldehyde in $0.1 \mathrm{M}$ phosphate buffered saline (PBS), $\mathrm{pH} 7.4$ for $72 \mathrm{~h}$ and transferred to PBS after this period. Each head was rapidly frozen at $-15^{\circ} \mathrm{C}$ and about $250 \mu \mathrm{m}$ were removed from the front of the head with a Leica CM1860 cryostat (Leica Biosystems Nussloch GmbH, Germany) in order to expose the part of the brain to be examined. Following the preparation, the material was defrosted at room temperature and stored in PBS.

Synapsin labeling was performed in whole mount samples in micro-test tubes in which the material was permeabilized with a solution containing $0.3 \%$ Triton-X100 and $5 \%$ bovine serum albumin for $1 \mathrm{~h}$, washed twice in PBS, and incubated for 4 days at $4^{\circ} \mathrm{C}$ in monoclonal antibody against synaptic vesicle-associated protein synapsin 1 of Drosophila (1:50; SYNORF1) diluted in PBS with $0.2 \%$ Triton-X100 and 5\% normal goat serum (NGS). The SYNORF1 was obtained from the Developmental Studies Hybridoma Bank developed under the auspices of the NICHD and maintained by The University of Iowa, Department of Biology, Iowa City, IA, USA.

Subsequently, the material was incubated in the secondary antibody Alexa Fluor-633 goat anti-mouse (Molecular Probes, OR, USA) (1:250 in PBS with $1 \%$ NGS) for $1 \mathrm{~h}$ at room temperature, according to procedures described by Hoyer et al. (2005). The synapsin-marked preparations were also labeled for F-actin with Alexa Fluor 488-Phalloidin (Molecular Probes, OR, USA) for $40 \mathrm{~min}$, and incubated in a solution containing DAPI (4',6-diamidino-2-phenylindole) for $10 \mathrm{~min}$ for nuclear staining. Finally, the material was mounted on special slides for inverted microscopy with ProLong ${ }^{\circledR}$ Gold antifade mounting medium (Molecular Probes, OR, USA).

The material was scanned at high resolution over a depth of $10 \mu \mathrm{m}$ at $0.17 \mu \mathrm{m}$ intervals ( $40 \mathrm{x}$, digital zoom $2 \mathrm{x}$ ) on a Leica Confocal Microscope TCS-SP5II (Leica Microsystems CMS, Wetzlar, Germany) with excitation performed with a $405 \mathrm{~nm}$ diode laser for DAPI, $488 \mathrm{~nm}$ argon laser for Alexa Fluor 488-Phalloidin, and $633 \mathrm{~nm}$ HeNe laser for Alexa Fluor-633 (synapsin). For fluorescence quantification, the conditions of laser intensity, gain and offset were also set in advance and kept at $10 \%, 1,100$, and -20 , respectively. We used the Leica Application Suite AF 2.6.0 software to process and quantify the fluorescence intensity related to synapsin labeling in the images.

A cortical region related to the olfactory lobes was chosen for quantitative assessment of synapsin expression at 
the different deltamethrin concentrations described above. The quantification was performed in maximum projections from three nonoverlapping measurements of 1,008,330 pixels areas in the selected region in each half of the brain, in order to obtain a mean value for each individual. The mean value of emitted fluorescence intensity was measured in gray scale.

Three individuals were analyzed for each concentration of insecticide and exposure time, and each one was a true replica. The data obtained were organized into groups formed by the intersection of the independent variables time and concentration and statistically evaluated by SPSS Statistics (SPSS v.22; Chicago, IL, USA) software. The data were first submitted to the Shapiro-Wilk normality test and Levene homogeneity test. Meeting the normality assumptions ( $p>0.1$ in all groups), but not the homocedasticity, the data were evaluated using the one-way analysis of variance with robust test for the equality of variance F-Brown-Forsythe, followed by the posthoc Games-Howell test, suitable for equal variances not assumed, according to the procedures described by Marôco (2014). A significance level $(\alpha)$ of 0.05 was considered.

\section{Results}

\section{Bioassays with G. olivaceus and Deltamethrin}

The millipedes employed in the bioassay had an average body weight of $2.51 \pm 0.48 \mathrm{~g}$, and no difference in the average masses was found between groups $\left(F_{4,115}=0.581\right.$, $p=0.677)$. During the bioassay, the millipedes belonging to the control group $\left(\mathrm{C}_{0}\right)$ were curled under the food or under the filter paper. Food consumption was noticed in all replicas.

The group exposed to the field concentration $\left(\mathrm{C}_{\mathrm{f}}\right)$ showed a similar behavior, except by releasing defensive secretion and gonopods eversion in one individual and more agitation of individuals than in the control group in the first $24 \mathrm{~h}$. No deaths were observed in either the $\mathrm{C}_{0}$ or $\mathrm{C}_{\mathrm{f}}$ groups, even after the $48 \mathrm{~h}$ of experiment.
In groups $C_{1}-C_{3}$, all individuals released a defensive secretion in the first hour of the experiment. Immediately after contact with the insecticide, all individuals of $\mathrm{C}_{2}$ and $\mathrm{C}_{3}$ showed oscillatory body movements. After $12 \mathrm{~h}, 75 \%$ of $\mathrm{C}_{1}$ had oscillatory and slow head movement but did not curl themselves; they remained stretched over the filter paper or turned upside down, exposing the ventral part of the body and moving the legs slowly (Fig. 1a). At $\mathrm{C}_{2}$ and $\mathrm{C}_{3}$, the higher concentrations, and after $24 \mathrm{~h}$, such behavior was also observed, but $80 \%$ of the millipedes were rolled and reacting subtly only when stimulated by a toothpick.

After $48 \mathrm{~h}$, gonopod externalization was observed in $60 \%$ of $\mathrm{C}_{1}$-collected males and $25 \%$ of $\mathrm{C}_{2}$-collected males. The integument became brittle in all individuals of $\mathrm{C}_{2}$ and $\mathrm{C}_{3}$, and three individuals of $\mathrm{C}_{2}$ had cracks where the hemolymph was leaking (Fig. 1b). The insecticide was able to cause mortality in diplopods at $C_{1}, C_{2}$, and $C_{3}$, but $C_{3}$ induced the highest number of deaths during the bioassay.

\section{Confocal Analysis of Synapsin Distribution}

In median cross-sections of G. olivaceus protocerebrum, synapsin immunolabeling was observed in the cortical region, as shown in Figure 2. The F-actin labeling was weak in the neuropil (Fig. 2a) and was located around neuron cell bodies. These F-actin labelings resembled boundaries within which the synapsin was immuno-localized (Fig. 2b).

Among the labeled somata, the antero-proximal region was selected for synapsin analysis because it is associated with the olfactory glomeruli's neuropilar region (Francisco et al., 2015) (Fig. 2a). The labeling was in the somata of neurons, exhibiting a distinctive granular texture (Fig. 2b).

With data from the quantification of fluorescence from synapsin immunolabeling in such a region, the F-Brown-Forsythe showed a significant difference in the mean fluorescence intensity between groups $\left(F_{14,13,095}=3,034\right.$, $p=0.026$ ), while the groups represent the different deltamethrin concentrations and times after the application. The Games-Howell posthoc test showed a significant difference
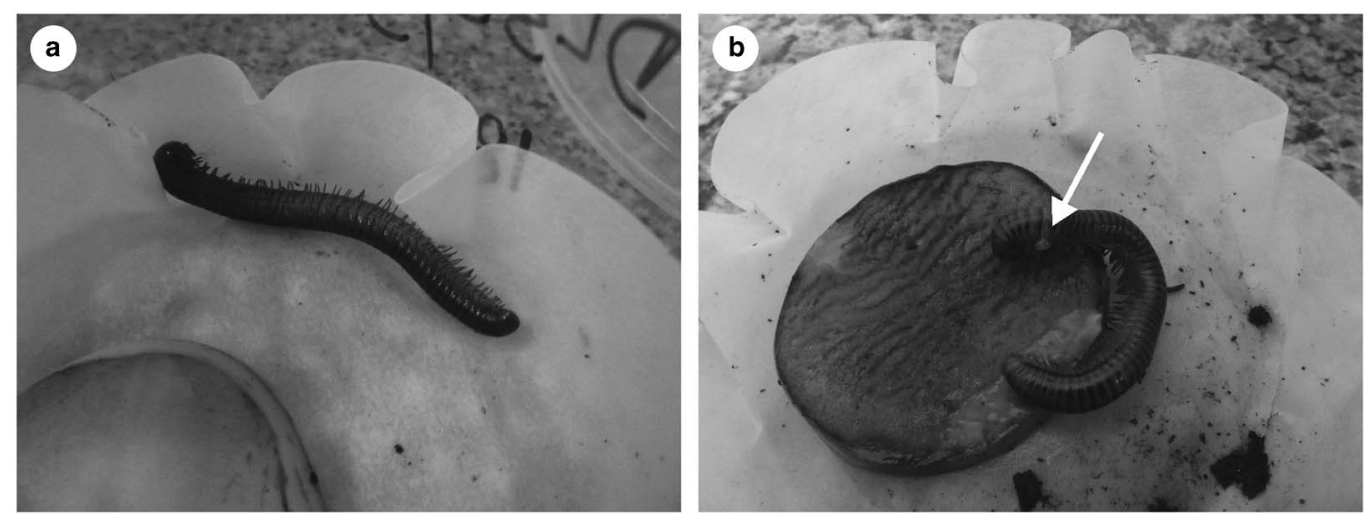

Figure 1. Millipedes exposed to deltamethrin. a: $\mathrm{C}_{1}$ millipede, $12 \mathrm{~h}$ after deltamethrin application, twisting itself and exposing the ventral part of the body. b: $\mathrm{C}_{2}$ millipede, $48 \mathrm{~h}$ after deltamethrin application. Arrow, crack in the integument. 

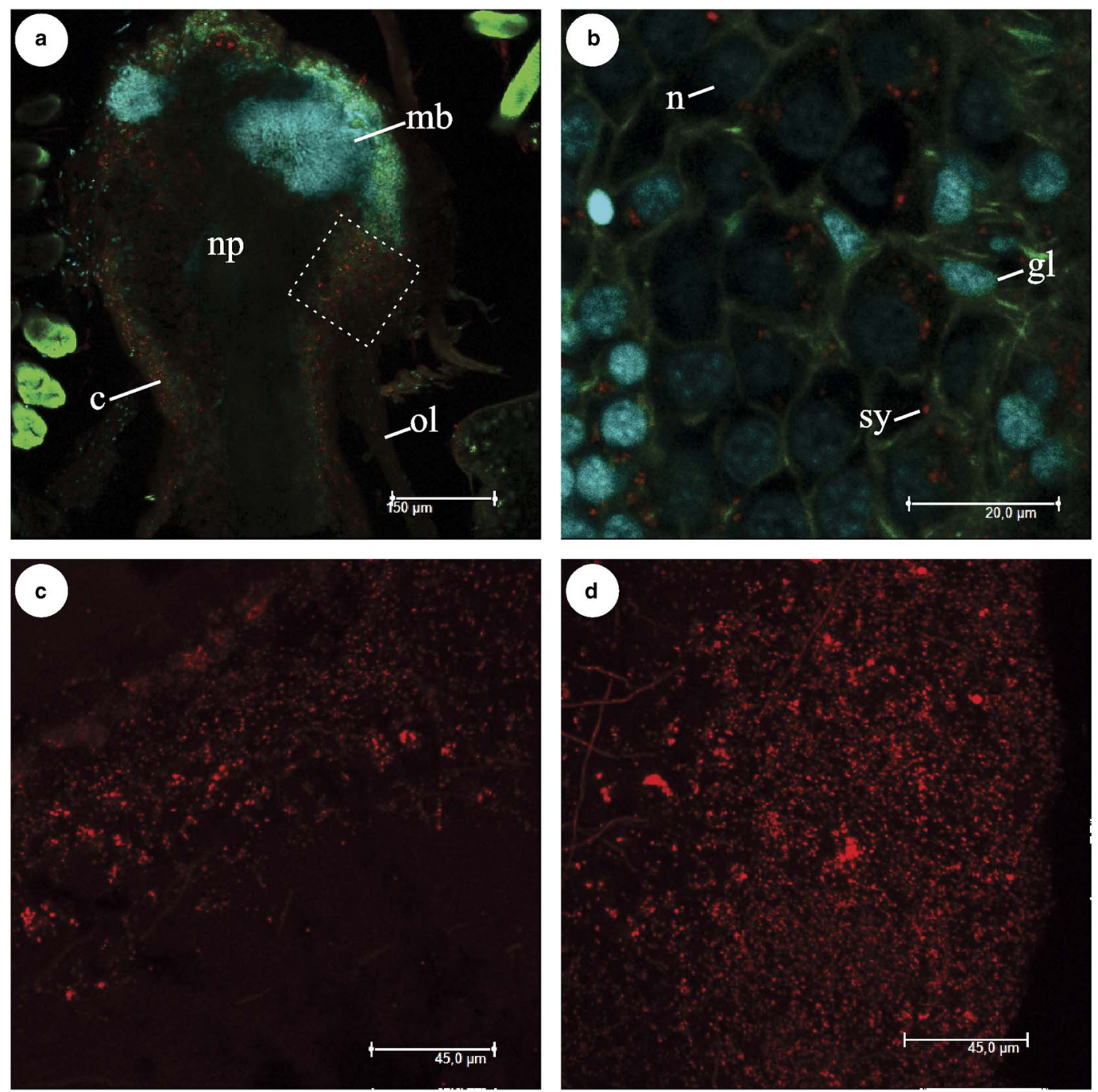

Figure 2. Maximum projections of confocal microscopy images, labeled with Anti-SYNORF1 and Alexa Fluor-633 (for synapsin) in red, Alexa Fluor 488-Phalloidin (F-actin) in green, and nuclei (DAPI) in cyan. a: Cross-section of half protocerebrum. The area within the square is the region selected for analysis. b: Synapsin labeling in the cortical cells of Gymnostreptus olivaceus' brain. c: Synapsin labeling in the control group $\left(\mathrm{C}_{0}\right)$. d: Synapsin labeling in the field concentration $\left(\mathrm{C}_{\mathrm{f}}\right)$. c, cortex; gl, glial cell nucleus; mb, mushroom body; $\mathrm{n}$, neuron nucleus; np, neuropil; ol, outer cell layer; sy, synapsin immunolabeling.

from control group only in $\mathrm{C}_{\mathrm{f}}$ and $\mathrm{C}_{1}$ after $12 \mathrm{~h}$ of exposure (Figs. 2c, 2d, 3, Table 1).

\section{Discussion}

In the present study, deltamethrin had a clear action on the millipede nervous system at the concentrations $\mathrm{C}_{1}, \mathrm{C}_{2}$, and $\mathrm{C}_{3}$, causing behavioral changes and movement abnormalities. At these concentrations, the insecticide also affected the animal's integument. Thus, besides the mortality observed here, the moribundity was high, since under natural conditions such millipedes would be completely vulnerable to predators and infections.

The data reported here suggest that one-fifth of the lethal dose $L_{50}\left(C_{1}\right)$ would be the minimum recommended for chemical control of millipedes with deltamethrin. However, this concentration is higher than that recommended by the manufacturers of commercial formulations and it is also higher than the field concentration adopted in this study, which did not cause mortality or moribundity in millipedes even after $48 \mathrm{~h}$.

Although chemical control of millipedes using deltamethrin is a popular practice, our results show that it would not be recommended, since only a high concentration of this product can cause mortality. These concentrations can harm nontarget organisms like honeybees. Decourtye et al. (2004) describes that a deltamethrin concentration of $500 \mu \mathrm{g} / \mathrm{kg}$ in syrup had a lethal effect on workers of the bee A. mellifera. Such syrup contamination decreased foraging activity and activity in the hive entrance. This concentration is lower than that which would be available in the environment by applying one-fifth of the $\mathrm{LD}_{50}$ of $\mathrm{G}$. olivaceus. 


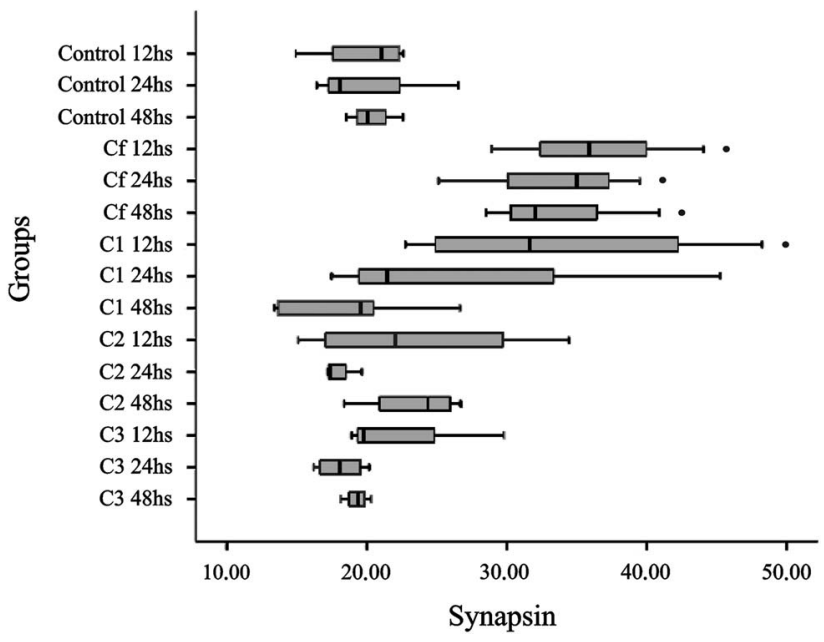

Figure 3. Box plot showing the range of means with standard deviations of the synapsin concentrations measured in the different groups. The dots indicate significant posthoc comparison according to the Games-Howell test $(p<0.05)$.

Deltamethrin is considered safe for mammals, however, studies using mice have shown it is capable of causing harming effects such as reduced density of muscarinic cholinergic receptors in the cerebral cortex of animals exposed to it during embryological development (Eriksson \& Fredriksson, 1991) and cerebral degeneration and apoptosis in exposed adult animals (Wu \& Liu, 2000a, 2000b; Chen et al., 2007). These results suggest caution in the use of this chemical.

When millipede brains were evaluated by synapsin immunolabeling, the staining pattern differed from what is usually described for other invertebrates. Anti-synapsin antibodies label synaptic vesicles (Groh et al., 2014). In most invertebrates, synapsin immunolabeling shows the presence of synapsin in neuropil regions, where synaptic contact between neurons occurs (Ott, 2008; Sombke et al., 2011). In the ant Cardiocondyla obscurior, the antibody against synapsin reacted strongly with synapses and was located mainly in neuropil compartments (Bressan et al., 2014). In G. olivaceus, in turn, synapsin was observed in cortical regions in the cell bodies of neurons. This feature suggests there are axosomatic or axodendritic synaptic contacts in these regions.
Furthermore, F-actin labeling was observed encircling neuronal cell bodies, while this labeling was weak and did not allow any distinction in the neuropil. In A. mellifera and in the centipede Glomeris marginata, phalloidin labeling occurred predominantly in axons and dendrites and allowed neuropil visualization (Groh et al., 2004; Sombke et al., 2011). Thus, the F-actin content of G. olivaceus is also distributed in a different way in the nervous system.

Functionally, the synapsins are responsible for keeping a reserve pool of synaptic vesicles that is not available for immediate release, and the maintenance of a dynamic balance between the reserve pool, the readily releasable pool, and the pool of vesicles engaged in the exo-endocytic cycle (Diegelmann et al., 2013). Therefore, synapsin establishes the extent of reserve pool synaptic vesicles and thus determines the availability of vesicles to exocytosis in the subsequent cycles (Hifiker et al., 1999).

Nevertheless, synapsins are not essential for synaptic transmission, even though they are important proteins for fine adjustment of synapse formation, remodeling, and plasticity (Benfenati, 2011; Humeau et al., 2011). In addition, synapsins are involved in neurotransmitter release regulation (Hifiker et al., 1999) and may be necessary for achieving appropriate associative functions (Diegelmann et al., 2013).

An increase in synapsin levels was observed after exposure of G. olivaceus to the lower concentration of deltametrhin used here. Considering that the antibody against synapsin labels both free and bound synapsin, this observation may lead to two hypotheses. (1) It can be supposed that an increased amount of synapsin means an increase in the reserve pool of synaptic vesicles. Synapsin tethering synaptic vesicles to the cytoskeleton ensures that the neurotransmitters present inside them are released in the subsequent cycles of exocytosis. Consequently, an increased amount of synapsin may mean abundance of synaptic vesicles available for exocytosis, with no disruption of synapsin function, but rather an increased synaptic activity. (2) Alternatively, it can be supposed that an increased amount of synapsin means a shift in the dynamic equilibrium between the different pools of vesicles because synapsins may be phosphorylated, resulting in fewer vesicles available for release and therefore less synaptic activity.

Table 1. Synapsin Average Concentration at Different Concentrations of Deltamethin and Exposure Times, with Statistical Analysis.

\begin{tabular}{|c|c|c|c|c|c|c|c|c|c|}
\hline \multirow[b]{2}{*}{$\begin{array}{l}\text { Exposure } \\
\text { Time }\end{array}$} & \multicolumn{5}{|c|}{ Average Concentration of Synapsin } & \multicolumn{4}{|c|}{ Posthoc Test (Games-Howell) } \\
\hline & Control & $\mathrm{C}_{\mathrm{f}}$ & $\mathrm{C}_{1}$ & $\mathrm{C}_{2}$ & $\mathrm{C}_{3}$ & $\begin{array}{c}\mathrm{C}_{\mathrm{f}} \text { versus } \\
\text { Control }\end{array}$ & $\begin{array}{c}\mathrm{C}_{1} \text { versus } \\
\text { Control }\end{array}$ & $\begin{array}{c}\mathrm{C}_{2} \text { versus } \\
\text { Control }\end{array}$ & $\begin{array}{c}\mathrm{C}_{3} \text { versus } \\
\text { Control }\end{array}$ \\
\hline $12 \mathrm{~h}$ & $19.92 \pm 1.74$ & $36.28 \pm 4.37$ & $33.54 \pm 5.63$ & $23.38 \pm 4.20$ & $22.82 \pm 3.48$ & $0.000^{*}$ & $0.001^{\star}$ & 0.876 & 0.822 \\
\hline $24 \mathrm{~h}$ & $20.36 \pm 3.13$ & $33.21 \pm 4.25$ & $28.05 \pm 8.67$ & $18.06 \pm 0.79$ & $18.10 \pm 0.89$ & $0.000^{*}$ & 0.656 & 0.966 & 0.938 \\
\hline $48 \mathrm{~h}$ & $20.40 \pm 1.19$ & $33.80 \pm 3.67$ & $18.75 \pm 2.46$ & $23.43 \pm 1.81$ & $19.26 \pm 0.62$ & $0.000^{*}$ & 1.000 & 0.727 & 1.000 \\
\hline
\end{tabular}

Concentrations of synapsin are presented as mean \pm standard deviation.

Control received topical application of ultrapure water; $\mathrm{C}_{1}$ received one-fifth of the $\mathrm{LD}_{50}$ established, that is $30.8 \mu \mathrm{g} / \mathrm{g}$ of deltamethrin; $\mathrm{C}_{2}$ received the $\mathrm{LD}_{50}$, that is $154 \mu \mathrm{g} / \mathrm{g}$ of deltamethrin; $\mathrm{C}_{3}$ received twice the $\mathrm{LD}_{50}$, that is $308 \mu \mathrm{g} / \mathrm{g}$ of deltamethrin; and $\mathrm{C}_{\mathrm{f}}$ received a field concentration, that is $0.17 \mu \mathrm{g} / \mathrm{g}$ of deltamethrin. ${ }^{*}$ Statistically significant at 0.05 level. 
The effect of deltamethrin on synapsin may be a result of calcium-dependent ATPase inhibition, an effect described for both deltamethrin and other type II pyrethroids (Orchard, 1980; Clark \& Matsumura, 1982). ATPase inhibition leads to increased intracellular calcium levels. Calcium is essential for synapsin phosphorylation, which is required to mobilize the reserve pool of synaptic vesicles and to release them by exocytosis (Cesca et al., 2010). This mechanism corroborates the increased release of neurotransmitters triggered by deltamethrin (Orchard, 1980; Clark \& Matsumura, 1982; Soderlund \& Bloomquist, 1989; Soderlund et al., 2002) and may be related to the greater agitation in $\mathrm{C}_{\mathrm{f}}$, where significantly more synapsin was detected. Thus, it can be inferred that deltamethrin caused an increase in synapsin synthesis and increased intracellular calcium levels, triggering synapsin phosphorylation and providing high neurotransmitter release, with diplopod agitation as a behavioral consequence.

This effect lasted for $12 \mathrm{~h}$ at $\mathrm{C}_{1}$, the second lowest concentration. After this period, the synapsin labeling returned to levels similar to those measured in the control group. In this case, the high concentration of deltamethrin led to large amounts of intracellular calcium that phosphorylated the synapsins, which were dispersed in the cytoplasm. Synapsin functional disruption and synthesis decrease may also have occurred, causing a decrease in the amount of detectable synapsin.

A synapsin functional breakdown is expected to increase neurotransmitter release by increasing the amount of vesicles available for release. However, an inhibition of neurotransmitter release may occur if these dispersed vesicles are not held in place, but instead diffuse away from the vesicle pool in the cytoplasm and dissipate (Hifiker et al., 1999). In mutant Drosophila larvae lacking synapsins, synaptic vesicles are distributed over larger areas of the cytoplasm and they are not part of the reserve pool (Diegelmann et al., 2013).

In $\mathrm{C}_{2}$ and $\mathrm{C}_{3}$, the higher concentrations tested here, the synapsin levels were also similar to those found in the control. It should be highlighted that such concentrations, although not lethal to millipedes, are extremely high. In this sense, this absence of changes in synapsin levels can be explained by other physiological changes induced by the insecticide, which may have counterbalanced a synapsin synthesis stimulus. The lack of ATP, for example, may decrease the amount of free synapsin (Huttner et al., 1983).

\section{CONCLUSION}

The present study indicated an early effect on synapsin induced by the lowest concentration of deltamethrin, indicating a precocious response of the millipede brain to the insecticide exposure. Therefore, deltamethrin induced measurable changes in the millipede brain. Taken together with the availability of millipedes in almost all terrestrial environments, these observations pave the way for the use of diplopods in the assessment of contaminants neurotoxicity. However, synapsin, showed changes only at low concentrations of insecticide and provided several possibilities of physiological interpretations. In this way, synapsin is not precise about triggered effects and its use alone is not strongly justified. We should emphasize that synapsin levels were not evaluated in chronic insecticide exposure and the comments made here are valid only for acute exposure.

\section{ACKNOWLEDGMENTS}

This work was supported by Fundação de Amparo a Pesquisa do Estado de São Paulo-FAPESP grant 2012/24562-5. The authors also thank Thaisa Roat for providing the cryostat and Marcelo Francisco, Cristina Moreira de Sousa, Diego Simões dos Santos, Ana Claudia de Castro Marcato, Cleiton Souza, e Raphael Baston de Souza for helping with the experiment.

\section{REFERENCES}

Arab, A., Zacarin, G.G., Fontanetti, C.S., Camargo-Mathias, M.I., SAntos, M.G. \& CABrera, A.C. (2003). Composition of the defensive secretion of the Neotropical millipede Rhinocricus padbergi Verhoeff 1938 (Diplopoda: Spirobolida: Rhinocricidae). Entomotropica 18, 79-82.

Badiou, A. \& Belzunces, L.P. (2008). Is acetylcholinesterase a pertinent biomarker to detect exposure of pyrethroids? A study case with deltamethrin. Chem Biol Interact 175, 406-409.

Badiou, A., Meled, M. \& Belzunces, L.P. (2008). Honeybee Apis mellifera acetylcholinesterase-A biomarker to detect deltamethrin exposure. Ecotoxicol Environ Saf 69, 246-253.

Benfenati, F. (2011). Synapsins-Molecular function, development and disease. Semin Cell Dev Biol 22, 377.

Boccardo, L., Fernandes, M.N. \& Penteado, C.H.S. (2001). Toxicity of deltamethrin pyrethroid on neotropical millipedes, Gymnostreptus olivaceus and Plusioporus setiger. J Adv Zool 22, 1-4.

Boccardo, L., Jucá-Chagas, R. \& Penteado, C.H.S. (2002). Migration and population outbreaks of millipedes in the coffee plantations, region of Alto Paranaíba, MG, Brazil. Holos Environ 2, 220-223.

Bressan, J.M.A., Benz, M., Oettler, J., Heinze, J., Hartenstein, V. \& SPRECHER, S. (2014). A map of brain neuropils and fiber systems in the ant Cardiocondyla obscurior. Front Neuroanat 8, article no. 166, 12pp.

Cesca, F., Baldelli, P., Valtorta, F. \& Benfenati, F. (2010). The synapsins: Key actors of synapse function and plasticity. Prog Neurobiol 91, 313-348.

Chen, D., Huang, X., Liu, L. \& ShI, N. (2007). Deltamethrin induces mitochondrial membrane permeability and altered expression of cytochrome C in rat brain. J Appl Toxicol 27, 368-372.

Chi, P., Greengard, P. \& Ryan, T.A. (2003). Synaptic vesicle mobilization is regulated by distinct synapsin I phosphorylation pathways at different frequencies. Neuron 38, 69-78.

Clark, J.M. \& Matsumura, F. (1982). Two different types of inhibitory effects of pyrethroids on nerve $\mathrm{Ca}$ - and $\mathrm{Ca}+\mathrm{Mg}$ ATPase activity in the squid, Loligo pealei. Pestic Biochem Physiol 18, 180-190.

Cloudslaey-Thompson, J.L. (1949). Significance of migration in myriapods. Naturalist 2, 947-962.

Decourtye, A., Devillers, J., Cluzeau, S., Charreton, M. \& PhamDelĖgue, M. (2004). Effects of imadacloprid and deltamethrin on associative learning in honeybees under semi-field and laboratory conditions. Ecotoxicol Environ Saf 57, 410-419.

Diegelmann, S., Klagges, B., Michels, B., Schleyer, M. \& Gerber, B. (2013). Maggot learning and synapsin function. J Exp Biol 216, 939-951. 
Ebregt, E., Struik, P.C., Abidin, P.E. \& Odongo, B. (2004a) Farmers' information on sweet potato production and millipede infestation in north-eastern Uganda I. Associations between spatial and temporal crop diversity and the level of pest infestation. W J Life Sci 52, 47-68.

Ebregt, E., Struik, P.C., Abidin, P.E. \& Odongo, B. (2004b). Farmers information on sweet potato production and millipede infestation in north-eastern Uganda II. Pest incidence and indigenous control strategies. W J Life Sci 54, 70-84.

ERIKSSON, P. \& Fredriksson, A. (1991). Neurotoxic effects of two different pyrethroids, bioallethrin and deltamethrin, on immature and adult mice: Changes in behavioral and muscarinic receptor variables. Toxicol Appl Pharmacol 108, 78-85.

FontAnetTI, C.S. (1989). Moulting behaviour in Chelodesmid species (Diplopoda, Polydesmida). Rev Bras Biol 49, 1053-1055.

Fontanetti, C.S., Calligaris, I.B. \& Souza, T.S. (2010). A millipede infestation of an urban area of the city of Campinas, Brazil and premilinary toxicity studies of insecticide Bendiocarb ${ }^{\circledR}$ to the Urostreptus atrobrunneus Pierozzi \& Fonatnetti, 2006. Arq Inst Biol São Paulo 77, 165-166.

Francisco, A., Nocelli, R.C.F. \& Fontanetti, C.S. (2015). The nervous system of the neotropical millipede Gymnostreptus olivaceus Schubart, 1944 (Spirostreptida, Spirostreptidae) shows an additional cell layer. Anim Biol 65, 133-150.

Girardin, B.W. \& Stevesons, S. (2002). Millipedes-Health consequences. J Emerg Nurs 28, 107-110.

Golovatch, S.I. \& KIME, D. (2009). Millipede (Diplopoda) distribuitions: A review. Soil Organ 81, 565-597.

Groh, C., Kelber, C., Grübel, K. \& Rössler, W. (2014). Density of mushroom body synaptic complexes limits intraspecies brain miniaturization in highly polymorphic leaf-cutting ant workers. $\operatorname{Proc} R$ Soc B 281, 1-9.

Groh, C., Tautz, J. \& Rössler, W. (2004). Synaptic organization in the adult honey bee brain is influenced by brood-temperature control during pupal development. Proc Natl Acad Sci U S A 101, 4268-4273.

Hifiker, S., Pieribone, V.A., Czernik, A.J., Kao, H., Augustine, G.J. \& GREENGARD, P. (1999). Synapsin as regulators of neurotransmitter release. Philos Trans R Soc B 354, 269-279.

HopkIN, S.P. \& READ, H. J. (1992). The Biology of Millipedes. New York, NY, USA: Oxford University Press.

Hoyer, S. C., Liebig, J. \& Rössler, W. (2005). Biogenic amines in the ponerine ant Harpegnathos saltator serotonin and dopamine immunoreactivity in the brain. Arthropod Struct Dev 34, 429-440.

Humeau, Y., Candiani, S., Ghirardi, M., Poulain, B. \& Montarolo, P. (2011). Functional roles of synapsins: Lessons from invertebrates. Semin Cell Dev Biol 22, 425-433.

Huttner, W.B., Schiebler, W., Greengard, P. \& DE Camilli, P. (1983). Synapsin I (protein I), a nerve terminal-especific phosphoprotein. III. Its association with synaptic vesicles studied in a highly purified synaptic vesicle preparation. J Cell Biol 96, 1374-1388.

LARINI, L. (1999). Inseticidas Organossintéticos. In Toxicologia dos praguicidas, Larini, L. (Ed.), pp. 19-91. São Paulo: Editora Manole Ltda.

Leitinger, G., Pabst, M.A., Rind, F.C. \& Simmons, P.J. (2004). Differential expression of synapsin in visual neurons of the locust Schistocerca gregaria. J Comp Neurol 480, 89-100.
LORDELLO, L.G.E. (1954). Observações sobre alguns diplópodos de interesse agrícola. Anais da E S A "Luiz de Queiroz" 11, 69-79.

Marôco, J. (2014). Análise Estatística com o SPSS Statistics. Pêro Pinheiro: Gráfica Manuel Barbosa \& Filhos.

McCavera, S.J. \& Soderlund, D.M. (2012). Differential statedependent modification of inactivation-deficient $\mathrm{Na}$ v1.6 sodium channels by the pyrethroid insecticides S-bioallethrin, tefluthrin and deltamethrin. Neurotoxicology 33, 384-390.

Nijima, K. \& Shinohara, K. (1988). Outbreaks of the Parafontaria laminata group (Diplopoda: Xystodesmidae). Jpn J Ecol 38, 257-268.

ORChARD, I. (1980). The effects of pyrethroids on the electrical activity of neurosecretory cells from the brain on Rhodnius prolixus. Pestic Biochem Physiol 13, 220-226.

OтT, S.R. (2008). Confocal microscopy in large insect brains: Zincformaldehyde fixation improves synapsin immunostaining and preservation of morphology in whole-mounts. J Neurosci Methods 172, 220-230.

Petersen, H. \& Luxton, M. (1982). A comparative analysis of soil fauna populations and their role in decomposition processes. Oikos 39, 291-357.

RomelL, L.G. (1935). An example of myriapods as mull formers. Ecology 16, 67-71.

Ruppert, E.E., Fox, R.S. \& Barnes, R.D. (2005). Myriapoda. In Zoologia dos invertebrados-Uma abordagem funcionalevolutiva, Ruppert, E.E., Fox, R.S. \& Barnes, R.D. (Eds.), pp. 819-842. São Paulo: Editora Roca Ltda.

SChARF, M.E. (2003). Neurological effects of insecticides. In Encyclopedia of Pest Management, Pimentel, D. (Ed.), pp. 395-399. Boca Raton, FL: CRC Press.

Schubart, O. (1942). Os Myriapodes e suas relações com a agricultura. Pap Avulsos Dep Zool Secr Agric Ind Comer (São Paulo) 2, 205-234.

Soderlund, D.M. \& Bloomguist, J.R. (1989). Neurotoxic actions of pyrethroid insecticides. Annu Rev Entomol 34, 77-96.

Soderlund, D.M., Clark, J.M., Sheets, L.P., Mullin, L.S., Piccirillo, V.J., Sargent, D., Stevens, J.T. \& Weiner, M.L. (2002). Mechanisms of pyrethroid neurotoxicity: Implications for cumulative risk assessment. Toxicology 171, 3-59.

Sombre, A., Harzsch, S. \& Hansson, B.S. (2011). Organization of deutocerebral neuropils and olfactory behavior in the centipede Scutigera coleoptrata (Linnaeus, 1758) (Myriapoda: Chilopoda). Chem Senses 36, 43-61.

Wightman, J.A. \& Wightman, A.S. (1994). An insect and sociological survey of groundnut fields in southern Africa. Agric Ecosyst Environ 51, 311-331.

Winder, G.H., Dewar, A.M. \& DunNing, R.A. (1993). Comparisons of granular pesticides for the control of soil-inhabiting arthropod pests of sugar beet. Crop Prot 12, 148-154.

Wu, A. \& Liu, Y. (2000a). Apoptotic cell death in rat brain following deltamethrin treatment. Neurosci Lett 279, 85-88.

Wu, A. \& Liv, Y. (2000b). Deltamethrin induces delayed apoptosis and altered expression of p53 and bax in rat brain. Environ Toxicol Pharmacol 8, 183-189.

Zhou, T., Zhou, W., Wang, Q., DaI, P., Liu, F., Zhang, Y. \& Sun, J. (2011). Effects of pyrethroids on neuronal excitability of adult honeybees Apis mellifera. Pestic Biochem Physiol 100, $35-40$. 